\title{
General Approaches to Structurally Diverse Isocyanoditerpenes
}

\author{
Mary Elisabeth Daub, Philipp C. Roosen, and Christopher D. Vanderwal*(0) \\ Department of Chemistry, University of California, 1102 Natural Sciences II, Irvine, 92697-2025 California, United States
}

ABSTRACT: Since their discovery in the 1970s, the striking architectures and the unusual isonitrile functional groups of the isocyanoterpenes have attracted the interest of many organic chemists. The more recent revelation of their potent in vitro antiplasmodial activity sparked new endeavors to synthesize members of this family of secondary metabolites. In this Synopsis, we discuss three distinct strategies that each address multiple structurally different members of the isocyanoterpenes, ending with some of our group's recent contributions in this area.

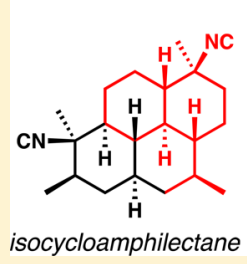

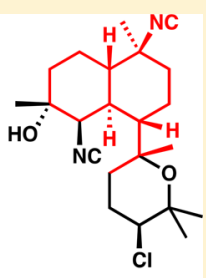

kalihinane

\section{INTRODUCTION}

Natural product synthesis can play a powerful role in interrogating the biological activity of the targets. ${ }^{1,2}$ Especially useful are synthesis designs that can provide access to many members within an extended family of complex secondary metabolites, as well as analogues designed to probe structureactivity relationships and/or mechanism of action. In this way, natural products that are scarcely available from nature might be procured in sufficient quantities for in depth studies, and analogues with significant changes to the native structurethose that could not be easily obtained by semisynthesis even if the natural products were plentiful-can be designed and created for the first time. ${ }^{3}$ The isocyanoterpene family of sponge-derived potent antiplasmodial agents ${ }^{4}$ is an attractive collection of molecules that might not at first appear well-suited to the development of such general approaches; however, three different strategies have now emerged that have each addressed multiple structurally distinct members of this family.

The first isocyanoterpene (ICT) to be described was axisonitrile-1 (1, Figure 1a) in 1973,5 followed by 9-

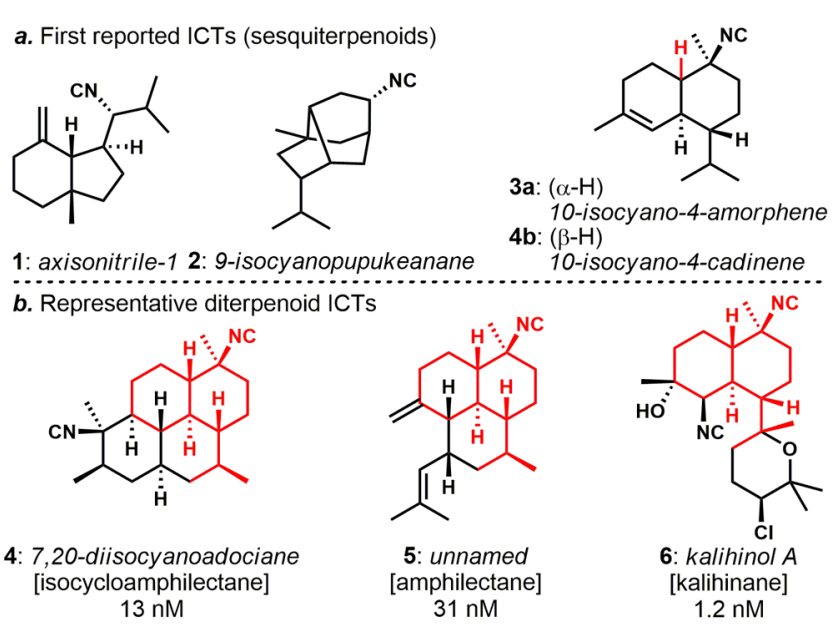

Figure 1. (a) Earliest reported isonitrile-containing terpenoids. (b) Skeletal diversity and antimalarial potency in the diterpenoid series. isocyanopupukeanane $(2)^{6}$ and 10-isocyano-4-amorphene $(3 a)^{7}$ a couple of years later. Wide structural diversity characterized these sesquiterpenoid compounds, and in most cases, naturally occurring analogues with isothiocyanates, isocyanates, or formamides in place of the isonitriles were coisolated. Later, many structurally diverse diterpenoid isonitriles were reported; representative structural families are shown in Figure $1 b .^{8}$ In spite of their considerable skeletal variability, there remains a shared substituted trans-decalin motif owing to a common biogenetic origin (highlighted in red in Figure $1 \mathrm{~b}$ ). ${ }^{8 \mathrm{f}}$ As a result of this recurring substructure, three rather general approaches have emerged in the synthesis of these targets: (1) an IMDA approach that was independently developed by several groups; (2) a dendralene approach established by Shenvi and co-workers; and (3) a chiral cyclohexenone-based approach from our research group. In this Synopsis, we will contextualize and describe each of these versatile approaches.

\section{THREE APPROACHES USED TO ACCESS MULTIPLE DIFFERENT ICT TARGETS}

Steady Increases in Complexity Define the First IMDA-Based Approaches toward the Diterpenoid ICTs. In studies not directed toward ICT natural product synthesis, Taber and Gunn reported an intramolecular Diels-Alder (IMDA) reaction in the synthesis of $( \pm)$-torreyol $(9$, Scheme 1). ${ }^{9}$ This key architecture-building reaction $(7 \rightarrow 8)$ readily constructed the key substituted decalin substructure (see Figure 1b) common to most ICT diterpenoids. The cis-decalin characteristic of torreyol (and found in isocyanoamorphene 3) was formed selectively, presumably via an endo-transition structure with the tether in a boat conformation. The potential was obvious for epimerization via a ketone enolate to the transdecalin more relevant to the majority of the ICTs, ${ }^{10}$ as well as the possibility of modulating the stereocontrol with respect to the ring junction in the cycloaddition event. This type of IMDA reaction was used to build DICA (4) by Corey and Magriotis; ${ }^{11}$ to achieve syntheses of DICA (formal) ${ }^{12}$ and amphilectane 5 , $^{13}$

Received: February 24, 2017

Published: April 12, 2017 


\section{Scheme 1. Taber's IMDA Approach to Torreyol}<smiles>C=CC(O)CCC(C=CC(=C)C)C(C)C</smiles>

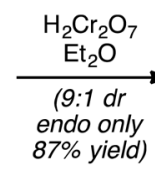

7

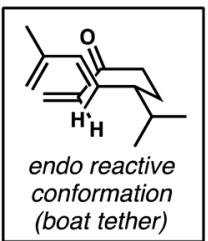

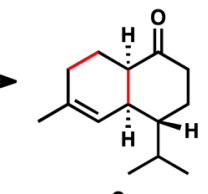

8

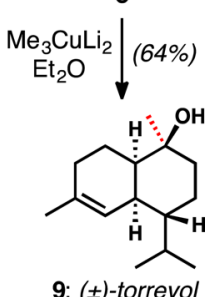

9: (土)-torreyol as well as total syntheses of several kalihinanes by Miyaoka and co-workers; ${ }^{14}$ and to synthesize kalihinol C by Wood and coworkers. $^{15}$

The pioneering synthesis of DICA by Corey and Magriotis features the steady buildup of the perhydropyrene scaffold of this complex ICT via judicious 2-fold application of the intramolecular Diels-Alder cycloaddition (Scheme 2). ${ }^{11}$ A close analogue of the IMDA reported by Taber and Gunn converts triene $\mathbf{1 0}$ into trans-decalin $\mathbf{1 1}$ in high yield and selectivity. The authors report that the unprotected enone undergoes spontaneous cycloaddition at ambient temperature to give the cis-decalin, in line with the previous findings of Taber and Gunn. With the dioxolane in place, high temperatures are needed to induce reactivity; however, proposed nonbonded interactions involving the dioxolane ring apparently disfavor the endo-cycloaddition transition structure and promote adoption of only one of two possible exo-cycloaddition modes. In several steps, the substrate for a second IMDA (12) is obtained, which undergoes high-yielding but poorly diastereoselective cycloaddition to 13. A few steps are needed to arrive at perhydropyrenedione 14, the "Corey dione", which is then converted in three relatively efficient steps to DICA (4). This endgame warrants discussion: equatorial nucleophilic methylation of each ketone, followed by trifluoroacetylation of both tertiary carbinols, sets up for isonitrile introduction under Lewis acidic conditions. Under the conditions shown, only the isonitrile regioisomers are apparently observed (that is, no nitriles are observed), but a mixture of all four possible diastereomers is obtained, owing to the presumed intermediacy of highly reactive carbocations. Pure DICA can be obtained by chromatography. ${ }^{16,17}$

White and Wood were the next to make use of the IMDA of Taber and Gunn; in fact, they made use of exactly cycloadduct 8 in a model study ${ }^{15 a}$ to establish the feasibility of their planned introduction of the isonitrile groups in eventual syntheses of kalihinane natural products. Shortly thereafter, they parlayed this work into a synthesis of kalihinol C (Scheme 3). ${ }^{15 \mathrm{~b}}$ The

Scheme 3. Wood Group's Synthesis of $( \pm)$-Kalihinol C Features a Taber-Type IMDA Followed by Epimerization to the trans-Decalin in 17
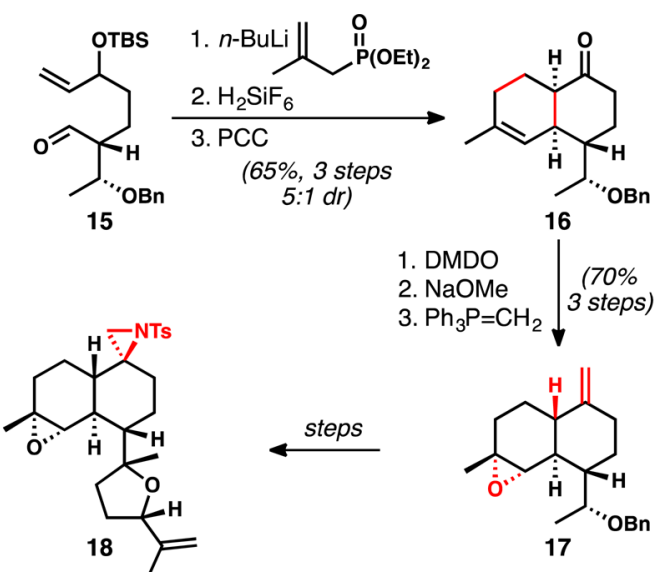

1. $\mathrm{LiEt}_{3} \mathrm{BH}$

2. $\mathrm{NaN}_{3}$

3. $\mathrm{Na}, \mathrm{NH}_{3}$

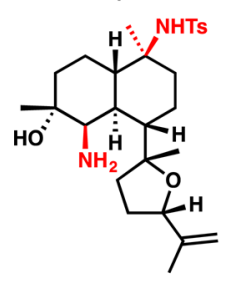

19
20: ( \pm )-kalihinol C

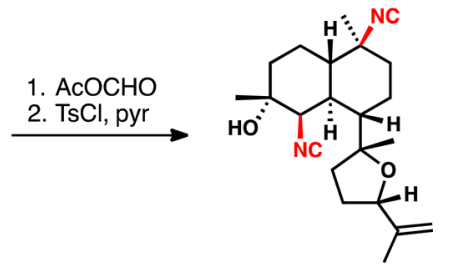

key IMDA precursor, generated by Horner-WadsworthEmmons alkenylation of 15, desilylation, and oxidation to the

\section{Scheme 2. Synthesis of DICA by Corey and Magriotis}<smiles>C=C/C=C\C(CCC1(CCOC(C)(C)C)COCCO1)C(C)CCOC</smiles>

10
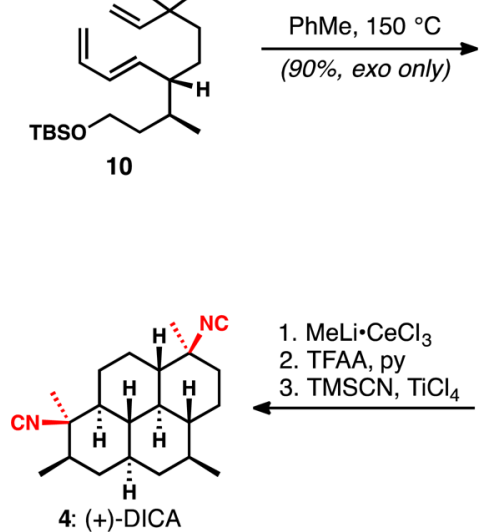

(+3 diastereomers)

3. TMSCN, $\mathrm{TiCl}_{4}$
1. $\mathrm{MeLi} \cdot \mathrm{CeCl}_{3}$

2. TFAA, py

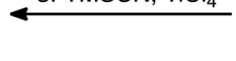

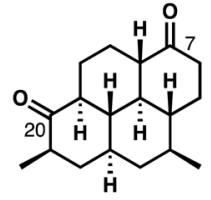

14: Corey dione

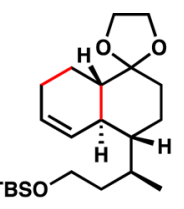

11
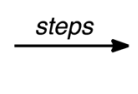

steps

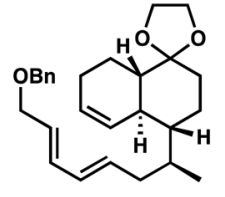

12
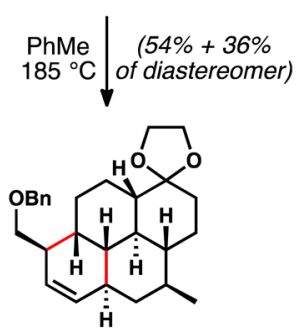

13

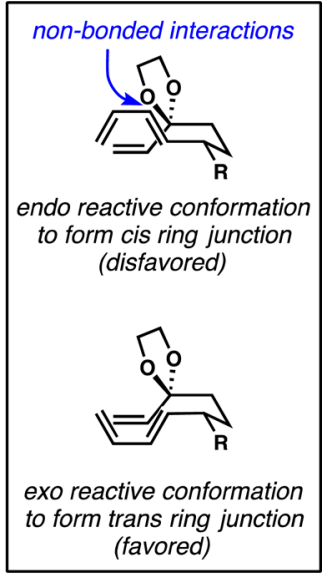

DOI: $10.1021 /$ acs.joc.7b00448 Org. Chem. 2017 acs.joc.7b00448 
trienone, undergoes spontaneous and selective cycloaddition to cis-decalin (16). Epoxidation of the C5-C6 alkene sets the stage for partial epimerization under basic conditions to the trans-decalin (60:40 dr). Epimerization was nearly complete (95:5 dr) after exposure to Wittig methylenation conditions, which delivers trans-decalin 17. Several steps were needed to install the THF ring, among which the exocyclic alkene is aziridinated with high stereocontrol, delivering 18. From there, manipulation of the aziridine and epoxide takes a total of five operations to give the two isonitriles of $( \pm)$-kalihinol C (20); the complete synthesis required about two dozen steps.

Miyaoka and co-workers made (+)-kalihinene X (23, Scheme 4), a cis-decalin kalihinane with a $\Delta^{4,5}$ alkene, from an

Scheme 4. Syntheses of (+)-Kalihinene $X$ and (+)-Kalihinol $\mathrm{A}$ by Miyaoka and Co-workers Featuring the Taber-Type IMDA Cycloaddition
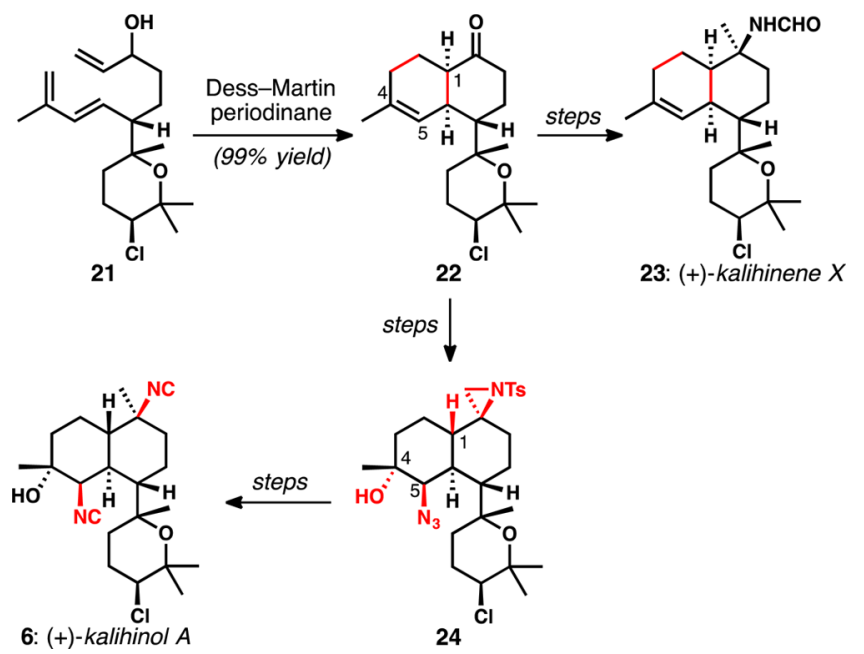

elaborated Taber-type triene (21). ${ }^{14 a}$ From the same cycloadduct (22), arrived at via a slightly improved route than in their synthesis of $\mathbf{2 3}$, the same group later made $(+)$-kalihinol $\mathrm{A},{ }^{14 \mathrm{~b}}$ the most potent ICT antimalarial yet tested. Epimerization at $\mathrm{C} 1$ to afford the trans-decalin was required and found to be quite efficient at the $\mathrm{C} 4-\mathrm{C} 5$ epoxide stage (not shown). Much of the chemistry used to install the isonitriles was similar to that used by Wood and co-workers, and the synthesis was completed in about 35 total steps. Using intermediates from their kalihinol A synthesis, they also synthesized the closely related diterpenoids (-)-kalihinol Y and (-)-10-epi-kalihinol I (not shown). ${ }^{14 \mathrm{c}}$ The major strategic differences in the efforts of the two groups involve the chronology of heterocyclic ring construction, which in both cases added significantly to the lengths of the routes: Wood's success suffered from a presumably unexpected multistep effort to append the THF ring onto the established decalin, while Miyaoka's work expended many operations to install the THP ring prior to cycloaddition. In short, while these approaches permitted an effective assembly of the decalin, they separated the challenges associated with that subgoal from those connected to the pendant C7-heterocycle, resulting in the longer overall sequences.

Miyaoka went on to use this IMDA strategy for the synthesis of an amphilectane-type ICT (Scheme 5$)^{13}$ and to achieve a formal synthesis of DICA (via the Corey dione, 14). ${ }^{12}$ The use of a silyloxy diene in the IMDA that forms 26 enabled a
Scheme 5. Synthesis of Amphilectane ICT ( \pm )-30 by Miyaoka and Co-workers

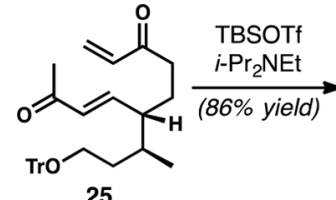

25

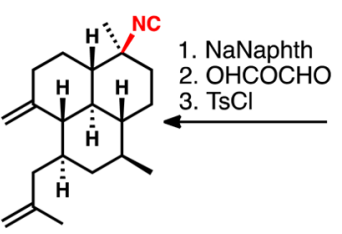

$( \pm)-30$<smiles>CC(C)OC1=C[C@@H]2[C@@H](CC1)C(=O)CC[C@@H]2C(C)C</smiles>

26

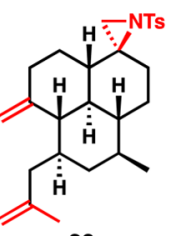

29

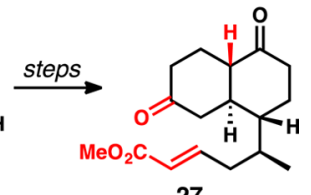

$\left.\square_{\mathrm{H}} \mathrm{CH}_{2} \mathrm{Cl}_{2}\right\rfloor_{\downarrow}^{27}(66 \%)$

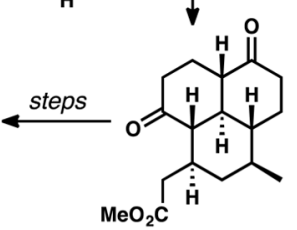

28 postcycloaddition hydrolysis to a C11-ketone (natural product numbering); ${ }^{13}$ in this context, the trans/cis thermodynamic ratio is much higher than in those with a $\mathrm{C} 11-\mathrm{C} 12$ alkene. An enamine Michael addition was used to forge the third ring of the target (see 28), and amphilectane 30 was obtained via straightforward manipulations.

Although Miyaoka's synthesis of the Corey dione (formal synthesis of DICA, Scheme 6) ${ }^{12}$ borrowed significantly in a

Scheme 6. Miyaoka Formal Synthesis of DICA via the Corey Dione Features C8 Epimerization in the Course of a Second IMDA Reaction To Afford the Tetracyclic Core

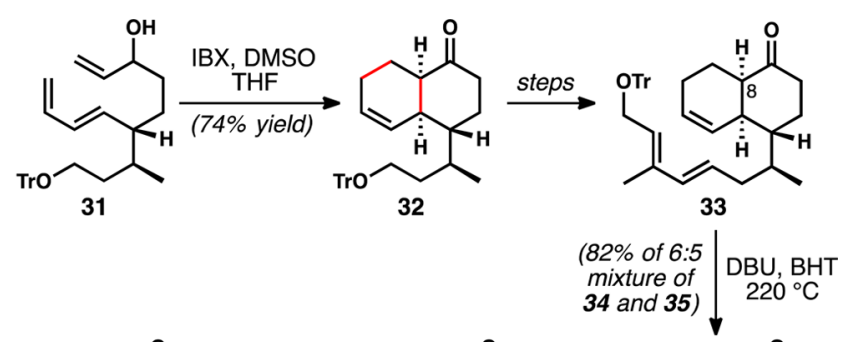

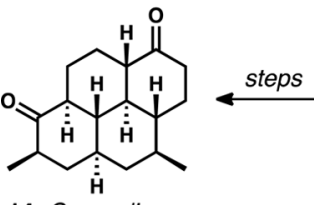

14: Corey dione

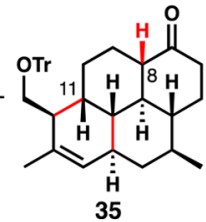

35

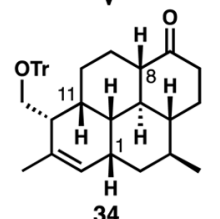

strategic sense from the Corey synthesis, a striking step involves the tandem epimerization/IMDA of $\mathbf{3 3}$ to forge tetracycles $\mathbf{3 4}$ and 35. The latter compound requires a few operations and epimerization at C11 to ultimately arrive at Corey dione $\mathbf{1 4}$. The overall stereocontrol of this IMDA is similar to that of Corey and Magriotis; however, the epimerization at C8 was complete under these conditions, suggesting that cycloaddition was hampered in the cis-decalin. Indeed, cycloaddition was not observed in the absence of base; had a productive IMDA occurred, it likely would have given a stereoisomer unusable for the synthesis. This nice result permits the productive use of the cis-decalin product that arises from the spontaneous cycloaddition of the trienone derived from 31. Interestingly, undesired cycloadduct 34 can also be converged to the Corey dione by epimerization at both $\mathrm{C} 11$ and $\mathrm{C} 1$ (not shown), although the yield is low. 
In short, the use of the Taber-Gunn IMDA has been exploited in the synthesis of DICA, several kalihinanes, and a representative amphilectane ICT. The hallmarks of these approaches by three different groups are the steady, but not explosive, buildup of the complexity of the ICT scaffolds. The positioning of the alkene resulting from the IMDA cycloadditions proved versatile for subsequent elaboration toward these three different classes of ICTs. The activating carbonyl provided the means of incorporation of the isonitrile at that position in all targets discussed above. The work discussed so far introduces the main methods for the introduction of the salient isonitriles: (1) the displacement of tertiary trifluoroacetate esters by TMSCN under Lewis acidic conditions; (2) the reductive cleavage of $\mathrm{N}$-tosylaziridines followed by detosylation, $\mathrm{N}$-formylation, and dehydration; and (3) in the case of the kalihinane $\beta$-hydroxyisonitrile, epoxide azidolysis, azide reduction, $\mathrm{N}$-formylation, and dehydration. ${ }^{18}$

The Shenvi Strategy: Rapid Scaffold Assembly by Tandem Cycloadditions. In 2014, Pronin and Shenvi reported a particularly direct synthesis of amphilectene ICT 5 (Scheme 7). ${ }^{19}$ Featuring the clever application of a

Scheme 7. Short Synthesis of $( \pm)-5$ by Pronin and Shenvi
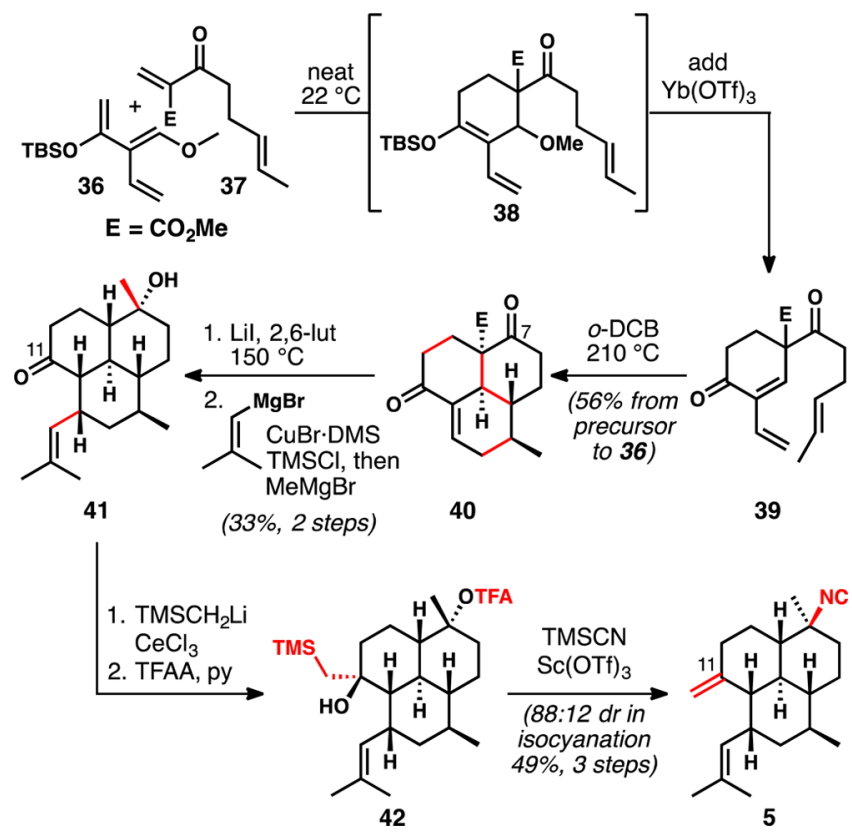

"Danishefsky dendralene" (36) in sequential cycloaddition reactions to build the tricyclic scaffold, this dendralene chemistry differs from the more typical "diene-transmissive" mode first adapted for natural product synthesis by Spino and $\mathrm{Liu}^{20}$ and exploited to great effect more recently by the group of Sherburn. ${ }^{21}$ In the case at hand, after an initial intermolecular Diels-Alder cycloaddition, decomposition of the resulting vinylogous acetal in $\mathbf{3 8}$ by the addition of $\mathrm{Yb}(\mathrm{OTf})_{3}$ generated trienone 39, which when heated underwent a second inverse electron demand cycloaddition in an intramolecular manifold. The intermediate relocation of the diene renders the dendralene disconnection much less obvious, even to the trained eye. Next, Krapcho decarboxylation provides the requisite trans-fusion from the original cis-cycloadduct, and stereocontrolled conjugate alkenylation of the enone followed by nucleophilic methylation of the remaining (unenolized) C7ketone efficiently delivers 41. To complete the synthesis, methylenation of the $\mathrm{C} 11$ ketone and isonitrile installation remained. Addition of trimethylsilylmethyllithium $/ \mathrm{CeCl}_{3}$ and selective activation of the less-hindered tertiary carbinol provided 42. Application of the new protocol developed for largely invertive isonitrile introduction, ${ }^{19,22}$ with concomitant Peterson-type elimination to install the $\mathrm{C} 11$ exocyclic alkene, completed the short synthesis of amphilectadiene 5. Although it is essentially an optimization of Corey's uncontrolled isonitrile introduction, ${ }^{11}$ the discovery of these conditions that presumably favor contact ion pairing over free carbocation chemistry is incredibly impactful for ICT synthesis. It is a particularly direct method to introduce the isonitrile (compare azide or protected amine $\rightarrow$ amine $\rightarrow$ formamide $\rightarrow$ isonitrile at a minimum; or ester $\rightarrow$ carboxylic acid $\rightarrow$ amine $\rightarrow$ formamide $\rightarrow$ isonitrile in a Curtius rearrangement approach). Moreover, and just as importantly, it permits the use of carbonyl chemistry to buildup the polycyclic ICT scaffold, prior to conversion of a ketone to a tertiary carbinol and thence to the isonitrile, a feature common to all three general approaches discussed herein.

Recently, this approach was extended to a beautiful synthesis of (+)-DICA (Scheme 8). ${ }^{23}$ The "Danishefsky dendralene" was built out to include a four-carbon unit for eventual construction of the fourth ring (see 43), and the stereochemical outcome of the cycloaddition was controlled via a chiral auxiliary on the dienophile (44). In that way, tricyclic intermediate 45, analogous to 40, was quickly assembled, but in optically pure form. After the C7-ketone was converted to the tertiary carbinol by equatorial delivery of a methyl group from tetramethylaluminum magnesium bromide, application of Shenvi's hydrogen-atom transfer (HAT) reduction protocol ${ }^{24}$ to the enone afforded $\mathbf{4 6}$ as the major product. The fourth ring was completed by an NHC-catalyzed benzoin-type closure on ketoaldehyde 47 , and deoxygenation of the resulting $\alpha$-ketol provided 48. This intermediate is closely related to the Corey dione, but with the C7-tertiary carbinol (equatorial methyl group) already introduced. For the purposes of DICA, application of Shenvi's method of stereocontrolled isonitrile introduction requires the C20-tertiary carbinol to have the methyl group oriented axially; typically, nucleophilic alkylations of conformationally constrained cyclohexanones result in the axial carbinol, with the alkyl group having attacked from an equatorial trajectory. Although methods exist to override this preference, Shenvi and co-workers utilized a Peterson alkenylation followed by an oxymercuration/reduction-based hydration to access 49 , which performed admirably in a double isonitrile installation. This synthesis is quite direct, and offers a vast improvement over previous work in the area, with its combination of both brevity and stereochemical control.

As a general approach to the polycarbocyclic ICTs, Shenvi's dendralene-based strategy is exceptionally direct, and the method for isonitrile installation is potentially broadly impactful. As this manuscript was in preparation, Reiher and Shenvi showed that this creative synthesis design could also be applied to the kalihinol problem (Scheme 9), in this case using a heterodendralene $(\mathbf{5 0}){ }^{25}$ In this case, after initial regular electron-demand cycloaddition of the Rawal-type diene ${ }^{26}$ and hydrolysis of the vinylogous hemiaminal that results, the $\alpha, \beta$ unsaturated carboxylic acid reacts via an IMHDA cycloaddition, thus controlling the configuration of the challenging stereotetrad. Most notably, this approach very cleverly solves the C7C11 stereochemical relationship, and permits rapid access to advanced intermediate $\mathbf{5 3}$ after Krapcho-like dephosphonyla- 
Scheme 8. Enantioselective Synthesis of (+)-DICA by the Shenvi Group

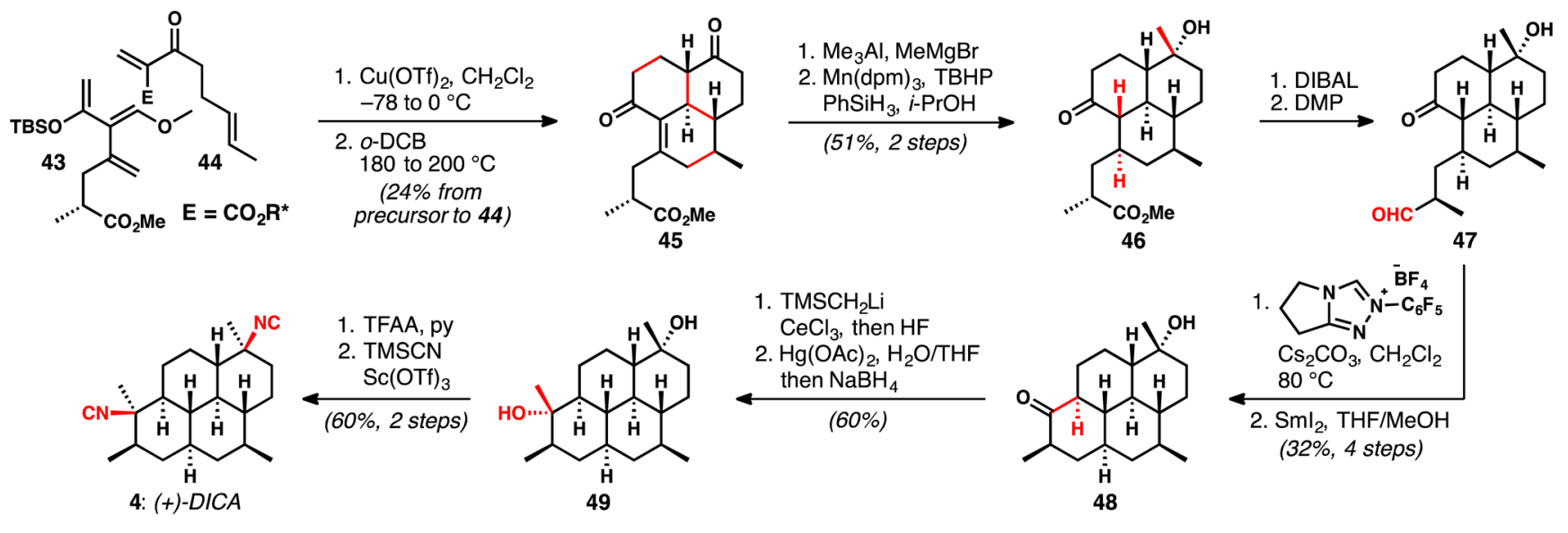

Scheme 9. Reiher and Shenvi's Synthesis of $( \pm)$-Kalihinol C Using Double Cycloaddition of Heterodendralene 50 To Install Key Stereochemical Relationships
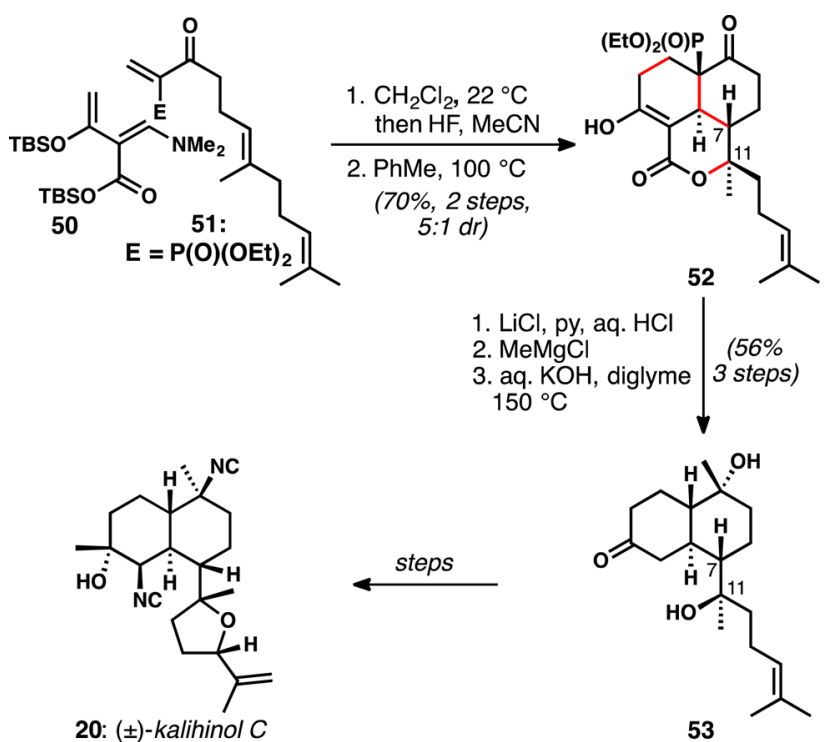

tion, nucleophilic methylation at $\mathrm{C} 10$, and ester hydrolysis/ decarboxylation. A number of steps are required to complete the synthesis of $( \pm)$-kalihinol C (20); however, the diastereocontrol throughout the route is uniformly high.

The clever double-cycloaddition strategy to the polycarbocyclic ICTs permits rapid assembly of the core structures of three different subgroups of these diterpenoids. The rather nonobvious application to the decalin system of the kalihinols led to high control in the formation of a difficult stereochemical relationship. From a methodological perspective, the invertive displacement of trifluoroacetates with TMSCN played a key role in each synthesis, as well as some of our own group's work, as discussed next.

The Vanderwal Approach: Substrate-Controlled Transformations of Chiral Cyclohexenones. Our approach to the ICTs was not initially planned for generality. Rather, we were focused on the potential challenges of the C7-C11 stereochemical relationship in the kalihinols, the so-called "attached ring" problem, ${ }^{27}$ that appeared to be causative of the length of some of the previous efforts toward these compounds. We sought to find a strategy to deal with that problem in tandem with the construction of the decalin ring system (Figure 2 ). It was our analysis of the relatively simple 10-isocyano-4-
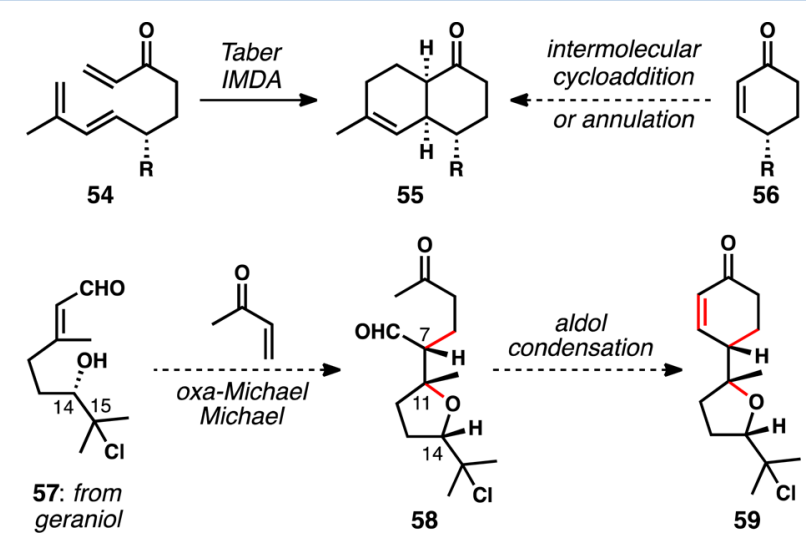

Figure 2. Inspiration for our kalihinol synthesis came from looking at other approaches to decalins of type $\mathbf{5 5}$.

amorphene and 10-isocyano-4-cadinene pair ( $3 \mathbf{a}$ and $\mathbf{3 b}$, respectively) that led initially to thinking about chiral cyclohexenones as precursors to ICT targets bearing the perhydropyrene (isocycloamphilectane, 5 ), perhydrophenalene (amphilectane, 6), and decalin (kalihinane, 7) scaffolds. Indeed, the cyclohexenone that we envisioned mapped clearly onto the conserved motif found among many of the most potent antimalarials in this class, as shown highlighted in red on the ICTs in Figure $1 \mathrm{~b}$.

Consideration of an intermolecular cycloaddition/annulation approach to decalins of type 55, in place of the wellprecedented Taber-Gunn-type IMDA featured many times in the syntheses outlined above, permitted the evolution of a strategy that merged an oxa-Michael approach to the pendant heterocycles and an organocatalytic asymmetric Robinson annulation to make the cyclohexenone precursor to the decalin $(\mathbf{5 7} \rightarrow \mathbf{5 8} \rightarrow \mathbf{5 9})$. Once this approach was identified, it was simple to see the connection to geraniol as a potentially versatile yet inexpensive starting material, and the opportunity for an end-game featuring concurrent introduction of both isonitriles presented itself. In its final form, this design permitted the rapid buildup of the kalihinol scaffold in a way that makes productive use of the chemistry afforded by the carbonyl group. We would later realize that chiral cyclohexenones that map onto the conserved portion of many ICTs 


\section{Scheme 10. Vanderwal Group Synthesis of Kalihinol B}
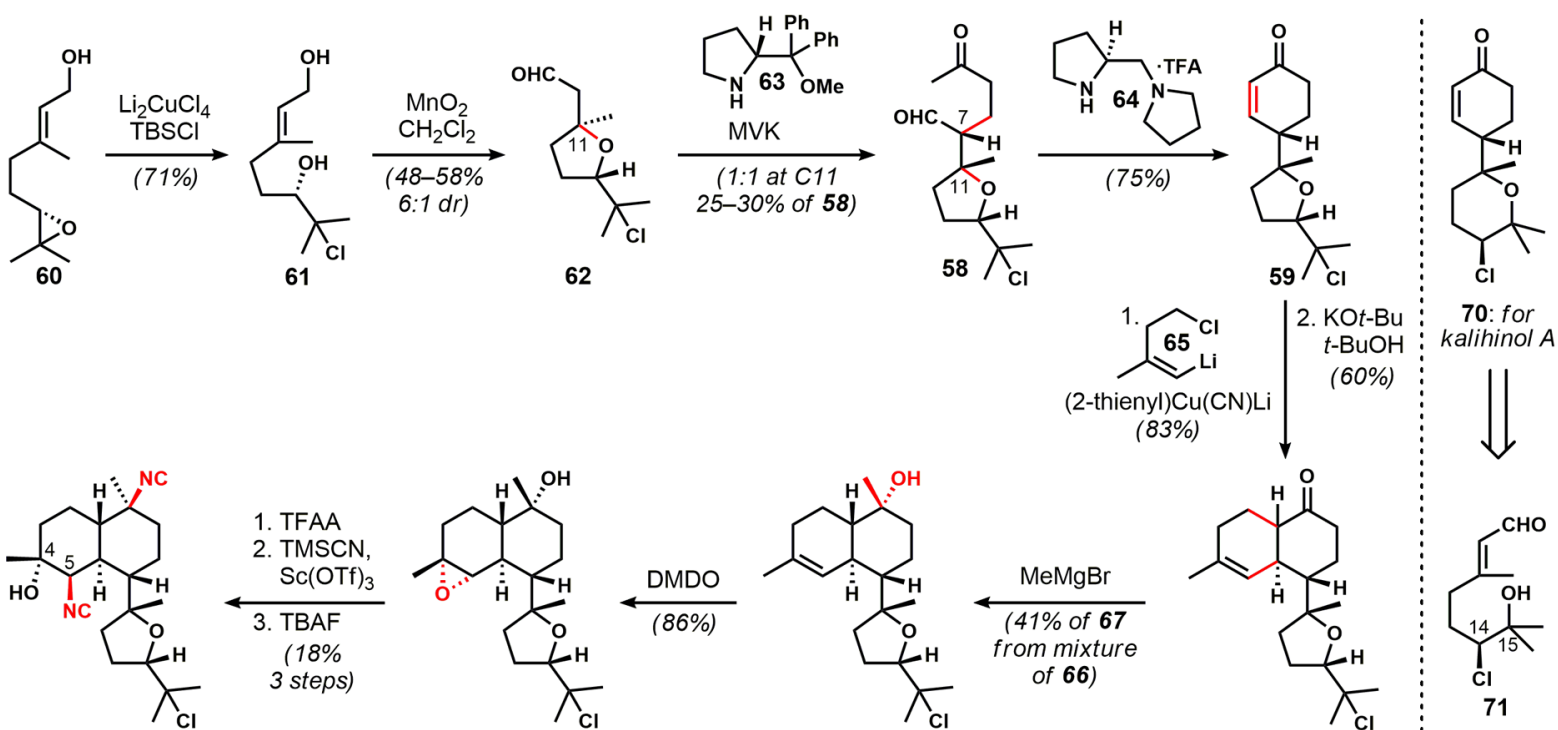

69: kalihinol B

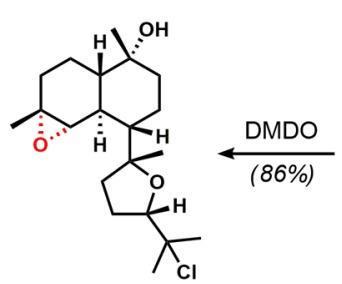

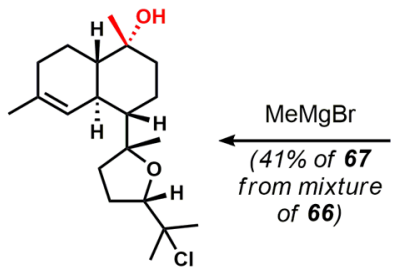

67

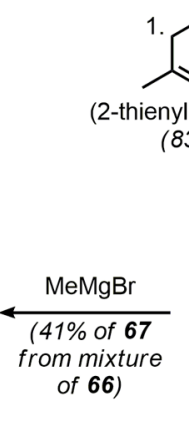

$\overbrace{}^{\mathrm{Li}}$

(83\%) (see red highlights in Figure 1b) could also provide starting platforms for the synthesis of isocycloamphilectane- and amphilectane-type ICTs.

Regiocontrolled chlorinolysis of geraniol epoxide (60) gave chlorohydrin 61 (Scheme 10), which upon oxidation presumably generated 57 (Figure 2); however, spontaneous oxa-Michael-type cyclization delivered THF 62 with predominantly the undesired configuration at C11. Exposure of $\mathbf{6 2}$ to methyl vinyl ketone and Gellman catalyst $63^{28}$ provided Michael adduct $\mathbf{5 8}$ as an equimolar mixture of diastereomers, differing in configuration at $\mathrm{C} 11$. We attributed the partial correction at this center to reversibility of the oxa-Michael cyclization under the organocatalytic reaction conditions. Aldol condensation with catalyst 64 provided key cyclohexenone 59, which was subjected to a Piers-type annulation ${ }^{29}$ to afford decalin 66. The mixture of cis- and trans-decalins thus formed was treated with methylmagnesium bromide to afford 67 and its diastereomer (cis ring junction), which were easily resolved. Epoxidation of $\mathbf{6 7}$ was highly stereoselective, ${ }^{15}$ and trifluoroacetylation of the tertiary carbinol of $\mathbf{6 8}$ set up for application of Shenvi's conditions for isonitrile introduction. ${ }^{22}$ For this route to remain concise, the conditions for invertive displacement of the tertiary trifluoroacetate also needed to effect isocyanolysis of the C4-C5 epoxide in a manner that was regiocontrolled with respect to the epoxide and with respect to isonitrile/nitrile selectivity. The latter point was not easily predictable. ${ }^{30}$ Fortunately, this reaction proceeded as desired, although in low yield, permitting a synthesis of kalihinol B (69) that was only 12 steps in longest linear sequence from geraniol, even while some selectivity issues would benefit from improvement. $^{31}$ A key advantage afforded by coupling the heterocycle formation to the decalin formation was that, by design, THP-containing kalihinols (cf. kalihinol A) could be accessed by virtually identical processes. These investigations, starting from chlorohydrins related to 71 , are ongoing.

Our concurrent efforts toward DICA suffered multiple setbacks ${ }^{32}$ until we recognized an opportunity to apply lessons learned from our kalihinol approach to this tetracyclic target. In other words, the substrate-controlled completion of kalihinol B from chiral cyclohexenone $\mathbf{5 9}$ appeared to be a concept that could be portable to the tricyclic amphilectanes and the tetracyclic congeners; it would simply require carefully chosen, stereocontrolled methods for introducing the remaining rings onto the starting chiral 4-substituted cyclohexenone scaffolds (Figure 3).

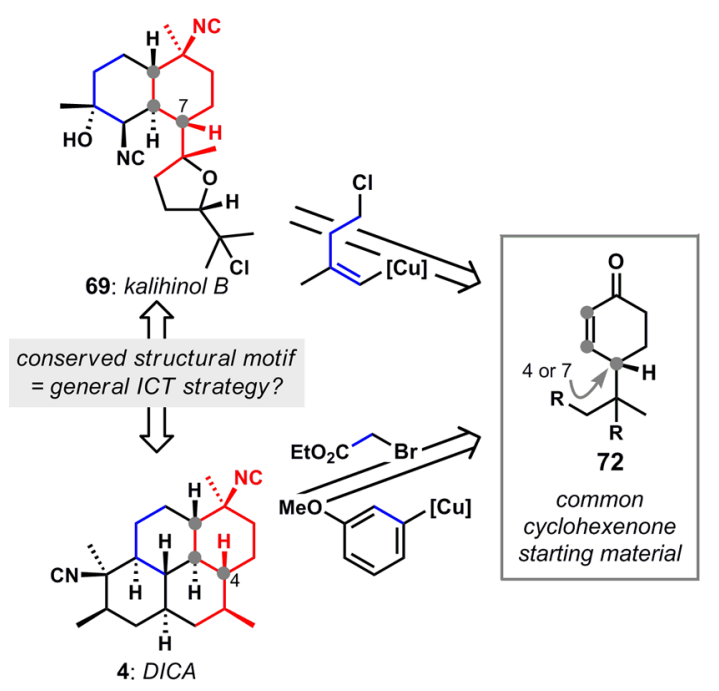

Figure 3. Plans to generalize a strategy based on substrate-controlled elaborations of chiral cyclohexenones from the kalihinols to other ICTs such as DICA.

In practice, a chiral pool approach was embraced for DICA, in place of the asymmetric Robinson annulation used in our kalihinol B synthesis. Known cyclohexenone (-)-73 is readily made starting from perillaldehyde, ${ }^{33}$ and tandem vicinal functionalization of the enone by conjugate arylation and enolate trapping was highly diastereoselective (Scheme 11). Subsequent reduction to $\mathbf{7 4}$ preceded cyclization to THF $\mathbf{7 5}$, which served to internally protect the diol for subsequent transformations. A formal alkene $\mathrm{C}-\mathrm{H}$ arylation was accomplished in two operations; alkene epoxidation proceeded smoothly, and the resulting epoxide was treated with acid to yield tetracycle 76 presumably via Meinwald rearrangement to 
Scheme 11. Vanderwal Laboratory's Formal Enantiospecific Synthesis of DICA via the Corey Dione
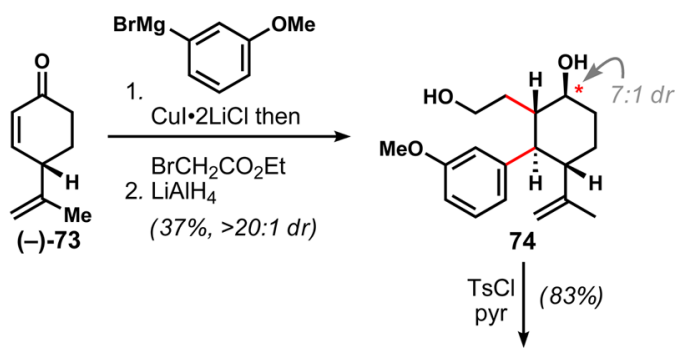

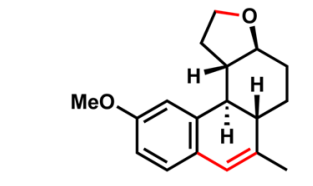

76
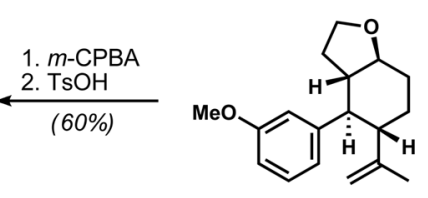

75
$\mathrm{Li}, \mathrm{NH}_{3}, \mathrm{MeOH}$ then aq. $\mathrm{HCl}$ THF, $-40^{\circ} \mathrm{C} \downarrow \begin{gathered}\mathrm{MeOH}, \mathrm{rt} \\ (65 \%)\end{gathered}$<smiles>C[C@H]1C[C@H]2CCC(=O)C=C2C2C3CCOC3CCC21</smiles>

77
1. $\mathrm{H}_{2}, \mathrm{Rh} / \mathrm{C}$ 2. $\mathrm{CrO}_{3}$

(38\%, 2 steps $15: 1 d r)$

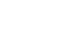
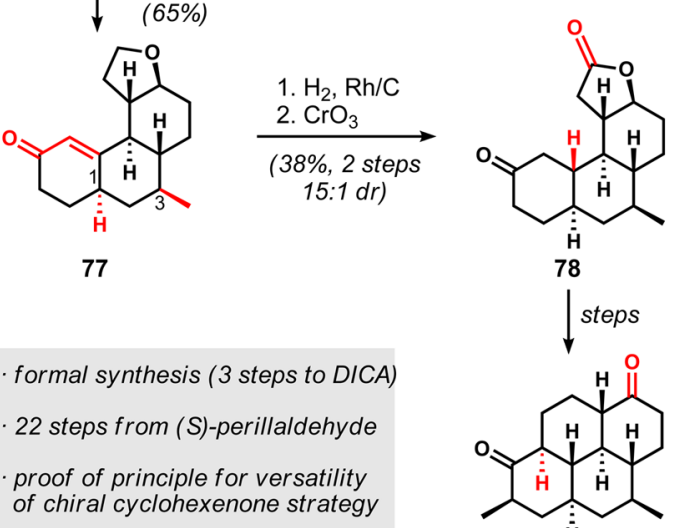

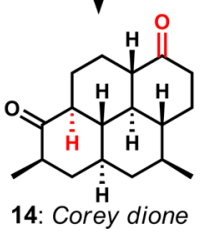

the aldehyde and Friedel-Crafts cyclodehydration. Three more stereogenic centers were set via complete reduction of the dihydronaphthalene substructure. Birch reduction followed by treatment with aqueous acid led to enone 77 with excellent levels of stereocontrol at both $\mathrm{C} 1$ and $\mathrm{C} 3$, and heterogeneous hydrogenation of the enone selectively afforded the trans-ring junction; at this stage chromium(III) oxide oxidation of the THF to the lactone, delivering $\mathbf{7 8}$, was needed to permit manipulation of that heterocycle such that the final ring of Corey dione could be formed. The elaboration of 78 to 14, although lengthy, validated the concept of using chiral cyclohexenones in approaches toward structurally different ICT targets. The lessons learned from this formal, enantiospecific synthesis of DICA ${ }^{34}$ has inspired a new, more streamlined route that is currently under investigation.

\section{CONCLUSIONS AND OUTLOOK}

The idea of finding general strategies toward whole classes of natural products is not a new one. In fact, in the past, practitioners of complex molecule synthesis might have spent decades working within a family of secondary metabolites, working out the details for each new achievement under the umbrella of an overarching strategy or a method developed to address a key challenge within that family. With our current level of sophistication in strategic design and with the wealth of powerful methods available, a significant focus has recently been and should remain on the deliberate introduction of flexibility into syntheses targeting bioactive natural products. This approach can facilitate access to many natural products and potentially valuable analogues only available by synthesis, and can reap rewards in biology.

Although each overarching strategy discussed above was quite different from the others, one underlying similarity is apparent: in most cases, a ketone precursor to an isonitrilebearing carbon was used to great effect in the construction of the scaffold in question. The reliance on carbonyl-based chemistry in three different yet effective approaches serves to remind us of the value of classical chemistry when applied in strategically creative ways.

There remains room for improvement in the synthesis of the ICTs; no synthesis yet has the combination of high stereochemical control and short route that could enable the material throughput needed should one of these compounds be selected for further development. However, very solid, general strategies are in place that should provide access to myriad unnatural analogues for preclinical studies and possible antimalarial lead identification. It seems reasonable at this stage, in fact, that focus might shift from efforts toward the synthesis of ICT natural products to the identification of potent analogues with improved physical properties. In that vein, we have recently disclosed the in vitro antiplasmodial activities of a collection of simplified kalihinol analogues that retain potent activity, ${ }^{35}$ and the Shenvi group has disclosed a small set of ICT analogues with high activity and also shown multistage in vitro efficacy. ${ }^{23}$ Hopefully, exciting times remain ahead for this family of natural products, as chemists and biologists dig deeper to understand their mechanism(s) of action and their potential as antimalarial agents.

\section{AUTHOR INFORMATION}

\section{Corresponding Author}

*E-mail: cdv@uci.edu.

\section{ORCID 우}

Christopher D. Vanderwal: 0000-0001-7218-4521

Notes

The authors declare no competing financial interest.

\section{Biographies}

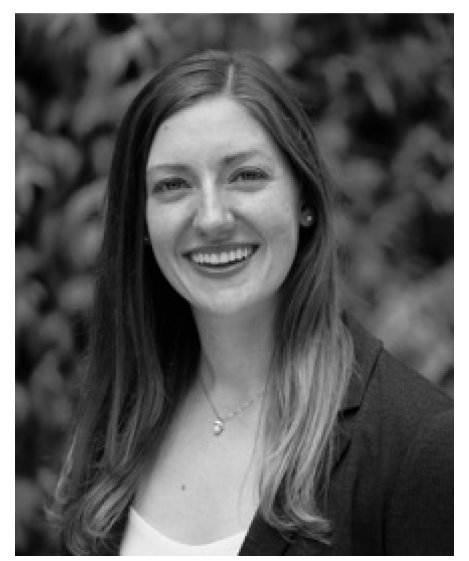

Mary Beth Daub received her Ph.D. in Organic Chemistry from the University of California, Irvine, in 2016 under the supervision of Professor Chris Vanderwal. She is currently a postdoctoral fellow in the research group of Professor Tehshik Yoon at the University of Wisconsin-Madison. Her research interests include the development of new synthetic methods and their application to the synthesis of natural products. 


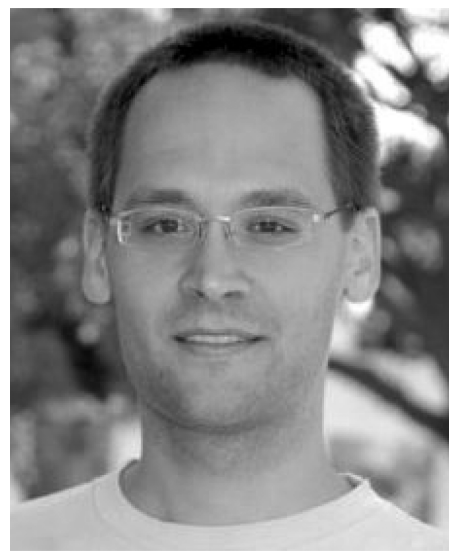

Philipp Roosen received an M.S. degree in organic chemistry (2011) from Michigan State University and completed a Ph.D. (2016) from the University of California, Irvine, under the guidance of Professor Christopher Vanderwal studying natural product synthesis. He joined Pivotal Drug Substance Process Development at Amgen in 2016.

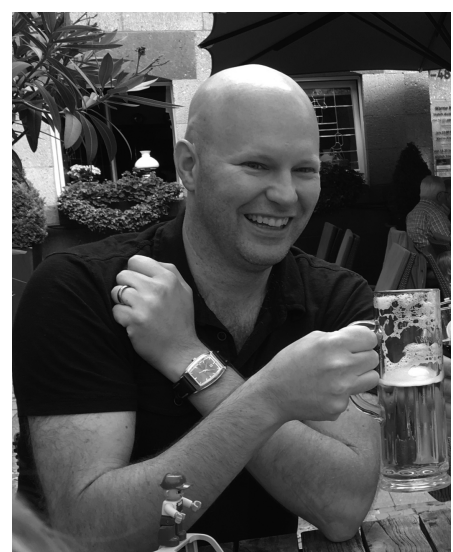

Christopher Vanderwal received a B.Sc. degree in Biochemistry (1995) and an M.Sc. degree in Chemistry (1998) from the University of Ottawa. He then moved to the Scripps Research Institute for doctoral studies in the group of Professor Erik Sorensen. After obtaining his Ph.D. in 2003, Chris joined the group of Professor Eric Jacobsen at Harvard University as a Jane Coffin Childs postdoctoral associate. In 2005, Chris began his independent academic career at the University of California, Irvine, where he is currently Professor of Chemistry. His research group develops strategies for the streamlined syntheses of complex bioactive natural products.

\section{ACKNOWLEDGMENTS}

We thank Professor Ryan Shenvi (Scripps Research Institute) for advance information regarding his laboratory's synthesis of kalihinol $\mathrm{C}$ so that it could be included in this article and, more generally, for the open lines of communication about their work in this area. M.E.D. was supported by a UCI Allergan Graduate Fellowship during her studies.

\section{REFERENCES}

(1) For a recent review, see: Hong, J. Chem. - Eur. J. 2014, 20, 10204-10212.

(2) For recent exemplary studies, see: (a) Xue, M.; Herzon, S. B. J. Am. Chem. Soc. 2016, 138, 15559-15562. (b) Mukherjee, H.; Chan, K.-P.; Andresen, V.; Hanley, M. L.; Gjertsen, B. T.; Myers, A. G. ACS Chem. Biol. 2015, 10, 855-863.

(3) (a) Seiple, I. B.; Zhang, Z.; Jakubec, P.; Langlois-Mercier, A.; Wright, P. M.; Hog, D. T.; Yabu, K.; Rao Allu, S.; Fukuzaki, T.; Carlsen, P. N.; Kitamura, Y.; Zhou, X.; Condakes, M. L.; Szczypiński,
F. T.; Green, W. D.; Myers, A. G. Nature 2016, 533, 338-345. (b) Charest, M. G.; Lerner, C. D.; Brubaker, J. D.; Siegel, D. R.; Myers, A. G. Science 2005, 308, 395-398.

(4) For a review of isocyanoterpenes, see: Schnermann, M. J.; Shenvi, R. A. Nat. Prod. Rep. 2015, 32, 543-577.

(5) Cafieri, F.; Fattorusso, E.; Magno, S.; Santacroce, C.; Sica, D. Tetrahedron 1973, 29, 4259-4262.

(6) Burreson, B. J.; Scheuer, P. J.; Finer, J.; Clardy, J. J. Am. Chem. Soc. 1975, 97, 4763-4764.

(7) Burreson, B. J.; Christophersen, C.; Scheuer, P. J. J. Am. Chem. Soc. 1975, 97, 201-202.

(8) 7,20-Diisocyanoadociane: (a) Baker, J. T.; Wells, R. J.; Oberhänsli, W. E.; Hawes, G. B. J. Am. Chem. Soc. 1976, 98, 40104012. (b) First amphilectane-type ICTs: Wratten, S. J.; Faulkner, D. J.; Hirotsu, K.; Clardy, J. Tetrahedron Lett. 1978, 19, 4345-4348. (c) Isolation of multiple ICTs, including 5: König, G. M.; Wright, A. D.; Angerhofer, C. K. J. Org. Chem. 1996, 61, 3259-3267. (d) Kalihinol A: Chang, C. W. J.; Patra, A.; Roll, D. M.; Scheuer, P. J.; Matsumoto, G. K.; Clardy, J. J. Am. Chem. Soc. 1984, 106, 4644-4646. (e) Isolation of multiple kalihinols, including kalihinol B: Chang, C. W. J.; Patra, A.; Baker, J. A.; Scheuer, P. J. J. Am. Chem. Soc. 1987, 109, 6119-6123. (f) Biosynthetic connections: Garson, M. J.; Simpson, J. S. Nat. Prod. Rep. 2004, 21, 164-179.

(9) Taber, D. F.; Gunn, B. P. J. Am. Chem. Soc. 1979, 101, 39923993.

(10) The relative stability of the cis- and trans-decalone systems is highly context dependent, and the means by which the trans isomer was obtained in the different syntheses are hallmarks of each achievement. Both kinetic and thermodynamic selectivities were leveraged to access the trans-ring junction, and more interestingly, kinetic preferences for reactivity of the trans-isomer under equilibrating conditions have been leveraged twice in the ICT context.

(11) Corey, E. J.; Magriotis, P. A. J. Am. Chem. Soc. 1987, 109, $287-$ 289.

(12) Miyaoka, H.; Okubo, Y.; Muroi, M.; Mitome, H.; Kawashima, E. Chem. Lett. 2011, 40, 246-247.

(13) Miyaoka, H.; Okubo, Y. Synlett 2011, 2011, 547-550.

(14) (a) Miyaoka, H.; Shida, H.; Yamada, N.; Mitome, H.; Yamada, Y. Tetrahedron Lett. 2002, 43, 2227-2230. (b) Miyaoka, H.; Abe, Y.; Sekiya, N.; Mitome, H.; Kawashima, E. Chem. Commun. 2012, 48, 901-903. (c) Miyaoka, H.; Abe, Y.; Kawashima, E. Chem. Pharm. Bull. 2012, 60, 1224-1226.

(15) (a) White, R. D.; Wood, J. L. Org. Lett. 2001, 3, 1825-1827. (b) White, R. D.; Keaney, G. F.; Slown, C. D.; Wood, J. L. Org. Lett. 2004, 6, 1123-1126.

(16) The Piers and Mander groups made significant contributions in the synthesis of tricyclic and tetracyclic ICTs. Owing to space considerations and the fact that their approaches had not really been generalized within the broader ICT family, we have not explicitly discussed this work; for further information, we refer the readers to the primary literature and to ref 4 .

(17) Arguably, the creative work of Piers that led to syntheses of amphilectanes and a cycloamphilectane could be considered a fourth general approach; however, owing to the lack of application to the structurally different kalihinanes, we will not discuss it here. For references, see: (a) Piers, E.; Llinas-Brunet, M. J. Org. Chem. 1989, 54, 1483-1484. (b) Piers, E.; Romero, M. A. Tetrahedron 1993, 49, 5791-5800. (c) Piers, E.; Llinas-Brunet, M.; Oballa, R. M. Can. J. Chem. 1993, 71, 1484-1494. For an otherwise unpublished synthesis of 8-isocyano-10-cycloamphilectene from the Piers laboratory, see: (d) Schindeler, T. W. Ph.D. Thesis, University of British Columbia, 1998.

(18) Although not explicitly shown, the stereospecific Curtius degradation of acyl azides was also used with great success in some applications, including the work of Piers (ref 17) and of Mander: Fairweather, K. A.; Mander, L. N. Org. Lett. 2006, 8, 3395-3398.

(19) Pronin, S. V.; Shenvi, R. A. J. Am. Chem. Soc. 2012, 134, 1960419606. 
(20) Although dendralene double cycloadditions date back to the mid-1950s, Spino was the first to formalize application to polycyclic natural products: (a) Blomquist, A. T.; Verdol, J. A. J. Am. Chem. Soc. 1955, 77, 81-83. (b) Bailey, W. J.; Economy, J. J. Am. Chem. Soc. 1955, 77, 1133-1136. (c) Spino, C.; Liu, G. J. Org. Chem. 1993, 58, 817-819.

(21) (a) Hopf, H.; Sherburn, M. S. Angew. Chem., Int. Ed. 2012, 51, 2298-2338. (b) Mackay, E. G.; Sherburn, M. S. Pure Appl. Chem. 2013, 85, 1227-1239. (c) Newton, C. G.; Drew, S. L.; Lawrence, A. L.; Willis, A. C.; Paddon-Row, M. C.; Sherburn, M. S. Nat. Chem. 2015, 7, 82-86.

(22) Pronin, S. V.; Reiher, C. A.; Shenvi, R. A. Nature 2013, 501, 195-199.

(23) Lu, H.-H.; Pronin, S. V.; Antonova-Koch, Y.; Meister, S.; Winzeler, E. A.; Shenvi, R. A. J. Am. Chem. Soc. 2016, 138, 7268-7271. (24) Iwasaki, K.; Wan, K. K.; Oppedisano, A.; Crossley, S. W. M.; Shenvi, R. A. J. Am. Chem. Soc. 2014, 136, 1300-1303.

(25) Reiher, C. A.; Shenvi, R. A. J. Am. Chem. Soc. 2017, 139, 36473650.

(26) Kozmin, S. A.; Janey, J. M.; Rawal, V. H. J. Org. Chem. 1999, 64, 3039-3052.

(27) (a) Overman, L. E.; Pennington, L. D. Can. J. Chem. 2000, 78, 732-738. (b) Overman, L. E.; Velthuisen, E. J. J. Org. Chem. 2006, 71, 1581-1587.

(28) Chi, Y.; Gellman, S. H. Org. Lett. 2005, 7, 4253-4256.

(29) Piers, E. Pure Appl. Chem. 1988, 60, 107-114.

(30) Imi, K.; Yanagihara, N.; Utimoto, K. J. Org. Chem. 1987, 52, 1013-1016.

(31) Daub, M. E.; Prudhomme, J.; Le Roch, K. G.; Vanderwal, C. D. J. Am. Chem. Soc. 2015, 137, 4912-4915.

(32) Roosen, P. C.; Vanderwal, C. D. Org. Lett. 2014, 16, 43684371 .

(33) (a) Stevens, R. V.; Albizati, K. F. J. Org. Chem. 1985, 50, 632640. (b) Siegel, C.; Gordon, P. M.; Uliss, D. B.; Handrick, G. R.; Dalzell, H. C.; Razdan, R. K. J. Org. Chem. 1991, 56, 6865-6872.

(34) Roosen, P. C.; Vanderwal, C. D. Angew. Chem., Int. Ed. 2016, 55, $7180-7183$

(35) Daub, M. E.; Prudhomme, J.; Ben Mamoun, C.; Le Roch, K. G.; Vanderwal, C. D. ACS Med. Chem. Lett. 2017, 8, 355-360. 